\title{
Flow Stress Calculation of IN718 Alloy for Hot Continuous Rolling Process
}

\author{
Wentao Wang, Han Li, Ke Zhang and Fengli Sui* \\ School of Metallurgical Engineering, Anhui University of Technology, New City Eastern Area, Maxiang Road, Ma'anshan, China \\ *Corresponding author
}

\begin{abstract}
A flow stress calculation model considering the interval softening was established based on the the single- and double-hit true stress-strain curves of IN718 alloy for multiple-pass hot continuous rolling process. The data calculated by the single-hit flow stress model and the double-hit softening fraction model used in the flow stress calculation model are in good agreement with the experimental ones.
\end{abstract}

Keywords- IN718 alloy; flow stress model; softening fraction model; hot continuous rolling

\section{INTRODUCTION}

The IN718 alloy is extensively used to manufacture critical parts in aeronautical, astronautical, oil and chemical industries due to its excellent mechanical, physical and anticorrosion behavior. On purpose of higher productivity and convenient process adjustment, the hot continuous rolling is preferred production of this alloy round rod, but the flow stress calculation of IN718 alloy in that production is the key factor for the rolling force determination and the parameter optimization in the rolling process.

Since the flow stress model of IN718 alloy built in the lower strain rate range $0.001 \sim 1.0 \mathrm{~s}^{-1}$ [1] can not meet the demand of high speed rolling, the other models in a much wider range of thermodynamic parameters have been developed and the piecewise fitting [2] and the neural network [3] were separately used in these models. Even though the higher fitting precision has been achieved in the later ones, the application of them is still limited due to their expression form. The rolling speed in a hot continuous rolling process will be increased with the rolling pass increased, and the temperature of the rolling piece for IN718 alloy as well due to thermal effects [4]. On the other hand, the accumulated strain in the roll gap will be softened in the stand interval due to the recrystallization behavior under appropriate conditions [5]. Obviously, it is of great importance not only the flow stress calculation of IN718 alloy should be built in a wide strain rate range and in a suitable deformation temperature range, but the softening behavior should be also considered.

In order to accurately calculate the rolling forces in the round rod rolling process of IN718 alloy, the flow stress model and the softening model have been constructed in the temperature range $950 \sim 1100{ }^{\circ} \mathrm{C}$ and in the strain rate range $0.1 \sim 100 \mathrm{~s}^{-1}$, and the flow stress calculation for the hot continuous rolling process of this alloy round rod considering the interval softening was established.

\section{CONSTRUCTION OF MODELS FOR HOT CONTINUOUS ROLLING PROCESS}

In the multiple-pass hot rolling process, the metadynamic recrystallization is the main softening mechanism for IN718 alloy at high temperature after deformation due to the shorter interval time as the critical strain is attained in the former deformation process, therefore, the plastic rheological behavior in the deformation process and the softening behavior due to the metadynamic recrystallization should be considered in the flow stress calculation.

\section{A. Flow Stress Model and Critic Strain Model for Dynamic \\ Recrystallization}

The single-hit cylindrical compression experiments were operated on the Gleeble-3800 simulator in the temperature range $950 \sim 1100{ }^{\circ} \mathrm{C}$ and in the strain rate range $0.1 \sim 100 \mathrm{~s}^{-1}$, and the samples with the diameter of $8 \mathrm{~mm}$ and in the height of $15 \mathrm{~mm}$ [6] used in the experiments were machined from the hot square billet before hot rolling process. The chemical composition of the billet is as follow (wt. \%): C-0.044, Si-0.13, Mn-0.10, Ni-52.61, Cr-18.98, Mo-3.05, Nb-5.14, Al- 0.46, Ti-0.92 and Fe-the balance.

The stress-strain curves obtained in the experiments are shown in FIGURE I and a-d correspond the deformation temperatures 950, 1000, 1050 and $1100{ }^{\circ} \mathrm{C}$. According to the relation between the flow stress and the Zener-Hollomon parameter [7], the single-hit flow stress model of IN718 alloy has been regressed as (1) and (2) based on the data provided by these stress-strain curves. And the calculated stress values by (1) and (2) are illustrated in FIGURE I for comparison with the tested ones.

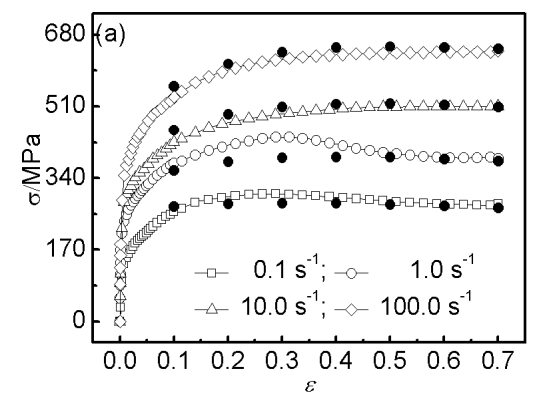

(a) 


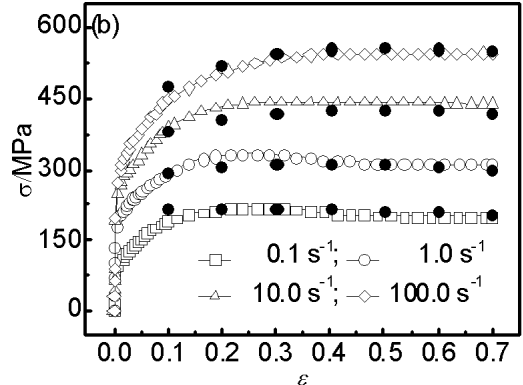

(b)

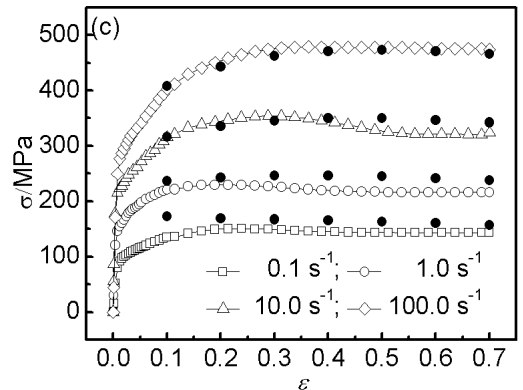

(c)

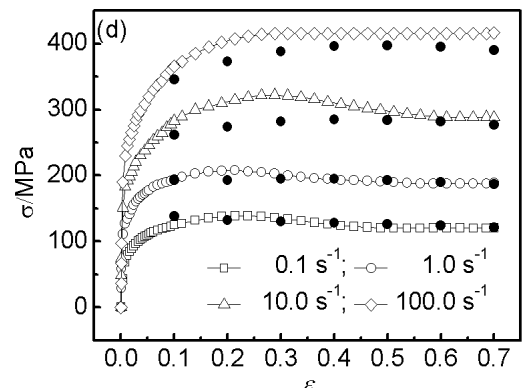

(d)

FIGURE I. STRESS-STRAIN CURVES IN THE SINGLE-HIT COMPRESSION EXPERIMENTS FOR IN718 ALLOY $(\bullet$ CALCULATED BY (1) AND (2)).

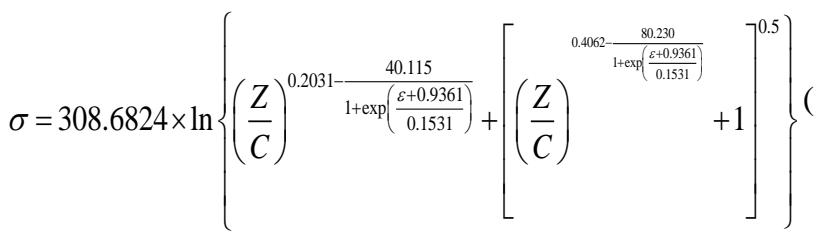

$$
\begin{aligned}
\frac{Z}{C}= & \operatorname{dexp}\left\{\frac{51481}{T+273}\left[0.3748 \times\left(\frac{\varepsilon+1.9286}{0.3+1.9286}\right)^{-3.0368}+0.6252 \times\left(\frac{\varepsilon+1.9286}{0.3+1.9286}\right)\right](2)\right. \\
& \left.-39.57316 \times\left[0.5727 \times\left(\frac{\varepsilon+0.885}{0.3+0.885}\right)^{-1.2543}+0.4273 \times\left(\frac{\varepsilon+0.885}{0.3+0.885}\right)\right]\right\}
\end{aligned}
$$

The critical strain $\left(\varepsilon_{c}\right)$ of IN718 alloy for the dynamic recrystallization expressed as (3) and (4) was calculated by the relation with the peak strain $[8,9]$.

$$
\begin{gathered}
\varepsilon_{c}=\frac{5}{6} \varepsilon_{p}=0.032675 Z^{0.04869} \\
Z=\operatorname{dexp}\{428667 /[R(T+273)]\}
\end{gathered}
$$

where, $T\left({ }^{\circ} \mathrm{C}\right)$ is the deformation temperature, $\&\left(\mathrm{~s}^{-1}\right)$ is the strain rate, $\varepsilon$ is the strain for deformation and $R(8.314$ $\left.\mathrm{J} \cdot \mathrm{mol}^{-1} \cdot \mathrm{K}^{-1}\right)$ is the gas constant.

\section{B. Softening Rate Model for Pass Interval}

The double-hit cylindrical compression experiments were operated in the temperature range $1000 \sim 1100{ }^{\circ} \mathrm{C}$ and in the strain rate range $0.1 \sim 10.0 \mathrm{~s}^{-1}$ on the same experimental installation with the same samples. The strain for the first deformation $\left(\varepsilon_{m}\right)$ is designed as $0.30,0.35$ and 0.40 and the whole strain is designed as 0.7 . The interval time between the first and the second deformations $(\Delta t)$ is designed as $1,5,10$ and $15 \mathrm{~s}$. The stress-strain curves obtained in the double-hit compression as $\Delta t=5 \mathrm{~s}, \varepsilon_{m}=0.35$ are shown in FIGURE II and a-c correspond to the strain rate of $0.1,1.0$ and $10.0 \mathrm{~s}^{-1}$. It can be seen the stress level for the second deformation is lower than that for the first one at the strain point $\varepsilon_{m}$, but the stress reduction degrees are different from the different strain rates, deformation temperatures and interval times. The $X_{s}$ named the softening rate is proposed to describe that degree.

The $X_{s}$ for the softening rate caused by the metadynamic recrystallization can be calculated by through the back extrapolation method and shown in (5) [10].

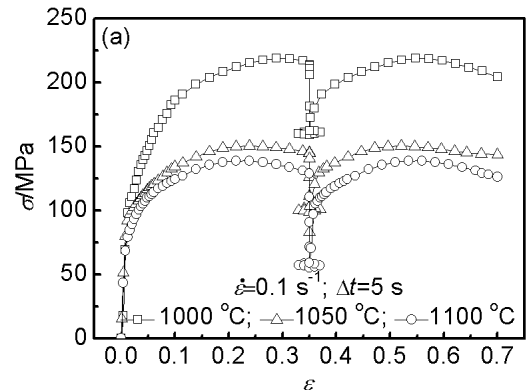

(a)

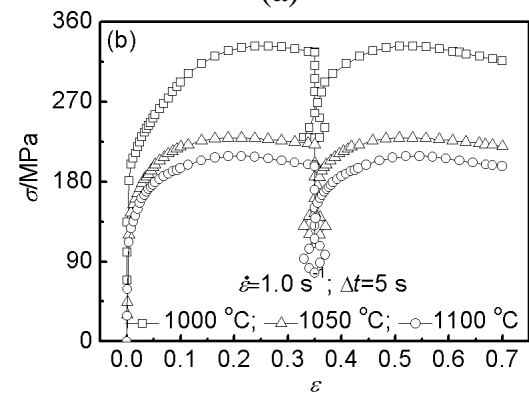

(b)

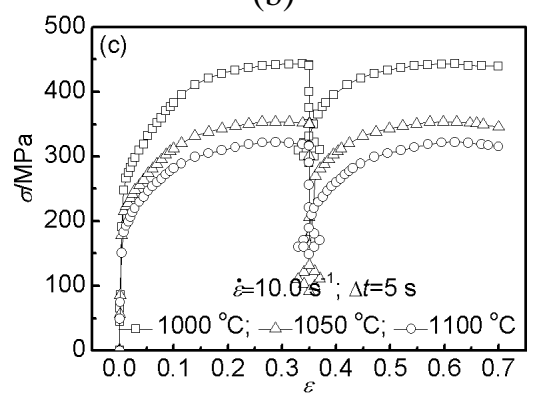

(c)

FIGURE II. STRESS-STRAIN CURVES IN THE DOUBLE- HIT FOR IN718 ALLOY. 


$$
X_{s}=1-\exp \left[-0.693\left(\frac{t}{t_{0.5}}\right)^{1.961}\right]
$$

where, $X_{s}$ is the softening fraction due to recrystallization; $t_{0.5}$ is the time for the recrystallization rate of $50 \%$ reached and regressed as (6).

$$
t_{0.5}=1.56 \times 10^{-3} \&^{0.079} \varepsilon^{-1.32} \exp \left(\frac{8751.51}{T+273}\right)
$$

The variation of $X_{s}$ with the interval time calculated by (5) and (6) is shown in FIGURE III and the tested values are marked in it. The higher fitting precision can be achieved by (5) and (6) by the comparison between the softening rate values calculated by (5) and (6) and through the back extrapolation method based on the tested curves.

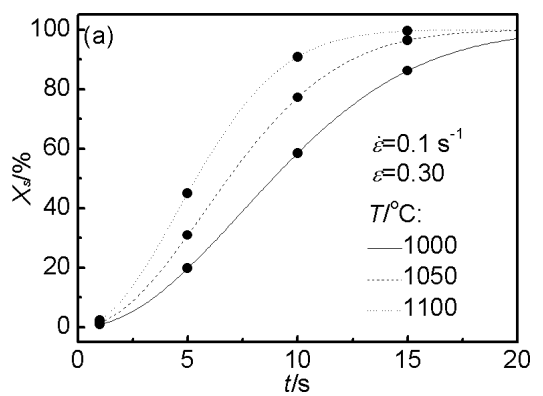

(a)

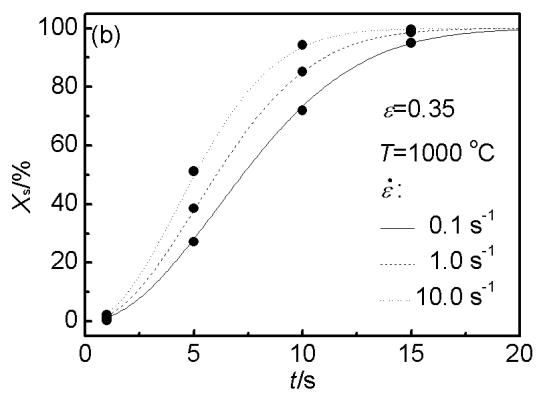

(b)

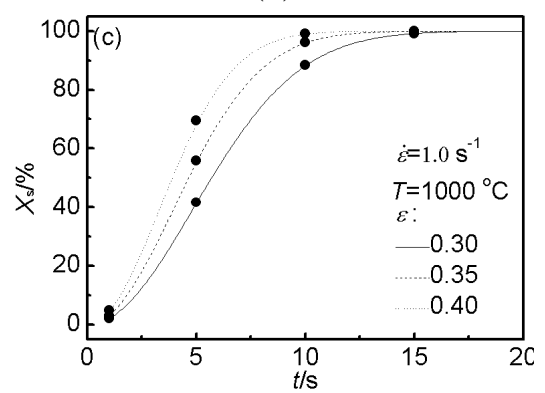

(c)

FIGURE III. COMPARISON BETWEEN THE CALCULATED AND THE TESTED XS AT DIFFERENT THERMODYNAMIC PARAMETERS.

\section{Calculation for the flow stress in a hot continuous rolling process}

The flow stress of IN718 alloy can be calculated by the adjustment of the strain $(\varepsilon)$ in (1) and (2) according to (7) and (8).

$$
\begin{gathered}
\varepsilon_{i}^{*}=\varepsilon_{i}+\varepsilon_{r_{i-1}} \\
\varepsilon_{r_{i-1}}=\varepsilon_{i-1}^{*}\left(1-X_{i-1}\right)
\end{gathered}
$$

where, $\varepsilon_{i}^{*}$ and $\varepsilon_{i-1}^{*}$ are the accumulated strain in the rolling process with the number $i$ and $(i-1)$ considering the deformation in the former rolling passes, $\varepsilon_{i}$ is the strain only caused by the deformation in the current rolling pass with the number $i, \varepsilon_{r_{i-1}}$ is the accumulated strain before the deformation of the rolling pass with the number $i, X_{i}-1$ is the softening rate calculated by (5) and (6) at the interval of the rolling passes with the number $i$ and $i-1$.

As the $\varepsilon$ in (1) and (2) is replaced with the $\varepsilon_{i}^{*}$ in (7), a flow stress of IN718 alloy for a hot continuous rolling process can be calculated and calculation flow chart is expressed as FIGURE IV.

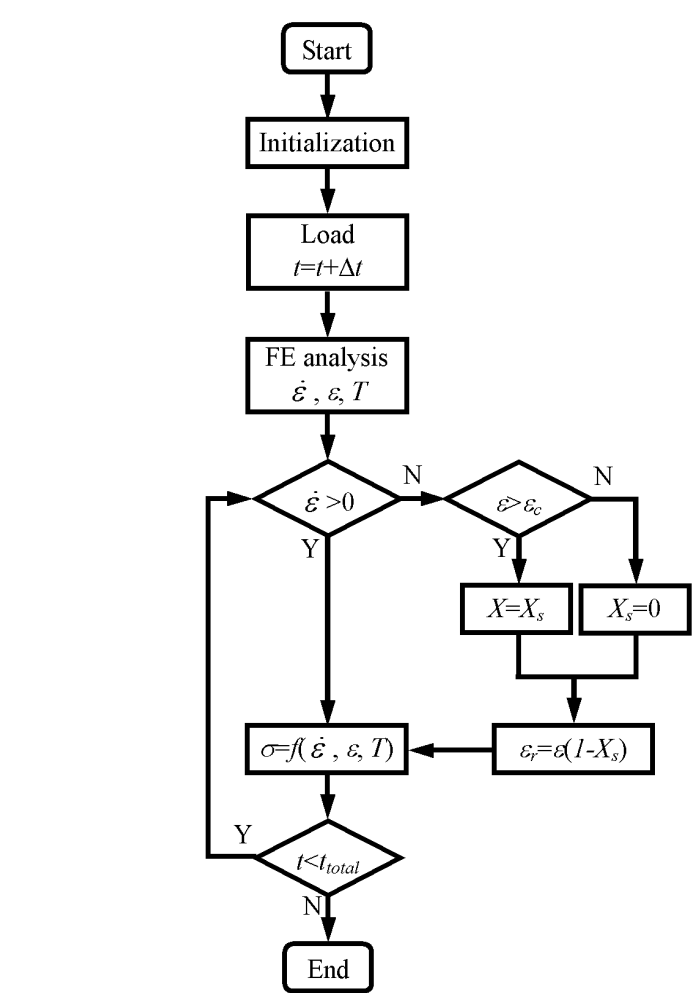

$$
\begin{aligned}
& \text { FIGURE IV. FLOW CHART OF DEFORMATION RESISTANCE } \\
& \text { CALCULATION DURING HOT CONTINUOUS ROLLING PROCESS. }
\end{aligned}
$$

\section{CONCLUSIONS}

A flow stress calculation model considering the interval softening for multiple-pass hot rolling process of IN 718 alloy was developed. The flow stress model for single-hit and the softening fraction model for double-hit used in the flow stress calculation model were verified by the comparison between the calculated and tested values. 


\section{ACKNOWLEDGMENTS}

The authors are grateful for the financial support from the National Natural Science Foundation of China (No.51674004) and the National Innovative Undertaking Plan Project for College Students (No.201710360003).

\section{REFERENCES}

[1] J.M. Zhang, Z.Y. Gao, J.Y. Zhuang, Z.Y. Zhong, Metall. Mater. Trans. A, vol. 30, pp.2701-2712, 1999.

[2] N.C. Guo, Z.J. Luo, Y. Cheng, D.H. Zhou, Acta Aeronaut. Astronaut. Sin., vol. 12, pp. 552-556, 1991. (in Chinese)

[3] G.L. Ji, F.G. Li, Prediction of the hot deformation constitutive behavior of superalloy IN-718 using an artificial neural network. International Conference on Physical and Numerical Simulation of Materials Processing. pp. 23-27, 2010.

[4] F.L. Sui, L.Q. Chen, X.H. Liu, L.T. Wang, W. Li, Acta Metall. Sin. (Engl. Lett.), 22 (2009) 81-90.

[5] T. Sakai, A. Belyakov, R. Kaibyshev, H. Miura, J.J. Jonas, Prog. Mater. Sci., 60 (2014) 130-207.

[6] F.L. Sui, Y. Zuo, J. Zhao, B.G. Ma, Acta Metall. Sin. (Engl. Lett.), 27 (2014) 494-500.

[7] F.J. Humphreys, M. Hatherly, Recystallization and related annealing phenomena, the first ed., Elsevier Science Ltd, UK, 1996.

[8] A. Laasraoui, J.J. Jonas, Metall. Trans. A, 22 (1991) 1545-1558.

[9] J.J. Jonas, H.J. McQueen, in: B. Baudelet (Ed.), Editions du Centre National de la Recherche Scientifique, Paris, 1976, pp. 99.

[10] D. Liu, Z.J. Luo, Chin. J. Nonferrous Met., 13 (2003) 1211-1218. (in Chinese)

[11] X.T. Li, M.T. Wang, F.S. Du, Mater. Sci. Eng. A, 408 (2005) 33-41.

[12] S. Kobayashi, S. Oh, T. Altan, Metal forming and the finite-element method, the first ed., Oxford University Press, New York, 1989.

[13] X.H. Liu, X. Shi, S.Q. Li, J.Y. Xu, G.D. Wang, J. Iron Steel Res., Int., 14 (2007) 22-26.

[14] F.L. Sui, Y. Zuo, X.H. Liu, L.Q. Chen, Appl. Math. Model, 37 (2013) 8776-8784. 